\title{
Dynamic Analysis of Excavator Arm Used for Breaking Operation
}

\author{
Weizhang Wang ${ }^{1}$, Kun Yang ${ }^{2}$, Zengmei Song ${ }^{1^{*}}$ \\ ${ }^{1}$ Institute of Mechanical Engineering, Weifang University, China \\ ${ }^{2}$ Institute of Mechanical Engineering, Shandong Science \& Technology University, China \\ *Corresponding Author.
}

\begin{abstract}
So far excavator retrofitting breaking hammer is commonly applied to impact breaking operation on rock, mountain and building body in engineering field. In practical operation fracture of the movable excavator arm frequently occurs. This thesis, in terms of dynamics, considers the breaking machine under three typical working conditions and aims at respective load solutions for the hinge point of the movable arm under each working condition. Modal analysis and harmonic response for the movable arm is conducted by means of finite element software. Analysis shows that the movable arm would not resonate at relatively high frequencies and external excitation load affects the movable arm noticeably at low frequencies. Damping increase of the working device of the breaking machine is needed to enable the external excitation frequency to avoid the primary and secondary inherent frequencies, and thus reduce the resonation opportunity of the movable arm.
\end{abstract}

Keyword: Movable arm, impact, finite element, mode, harmonic response

\section{Introduction}

The excavator is a machine widely used in engineering, covering about sixty percent of construction volume of geotechnical engineering. It plays a very important role in highway construction and mining [1].

Impact operation is necessary in mining, rock drilling and cutting and demolition of building. Replacing the excavator bucket with the breaking hammer forms a new engineering machine which is called breaking machine in this thesis [2].

Increase of breaking machine demand results in gradually increase of manufacturer. Increase in quantity requires higher performance of the breaking machine. Breaking operation of the breaking machine depends on the working device, so the performance of the working device directly affects the construction efficiency. Problems related to the working device thereupon occur despite fruitful impact and breaking of the breaking machine. Impact vibration of high frequency and the immense impact force greatly shorten the lifespan of the breaking machine, especially the frequent crack and fracture of its movable arm $[3,4]$.

In order to improve the high-strength torsion ability of the excavator movable arm, Bucyrus designed the movable arm as a circular cross-section structure, and achieved good results after applying advanced AC frequency conversion technology to the excavator [5]. In the study of excavator movable arm, Janmit Raj et al. Systematically designed a complete set of verification process for boom from many aspects, thus saving financial and material resources [6]. Zhang Enlai et al. Carried out modal analysis on the whole working device of excavator and obtained the corresponding modal analysis data. A variety of improvement measures were proposed based on analysis of the dynamic characteristics of the working device [7]. Asit Kumar Choudhary et al. carried out a series of finite element analysis on the excavator boom to ensure the safety of the design [8].

At present, most of the references merely analyze the working conditions of the excavator. This thesis attempts to

ISSN: 0010-8189

(C) CONVERTER 2020

www.converter-magazine.info 
discuss the movable arm of the breaking machine, aiming at providing references for solution of problems in the movable arm of the breaking machine.

\section{Selection of Working Condition and Solution of Load}

\subsection{Selection of working condition}

After assembly of the overall model of the working device, three respective working conditions are determined according to mutual adjustment of the oil cylinder, working condition one in which the breaking hammer operates vertically; working condition two in which the breaking hammer operates horizontally; working condition three in which the breaking hammer operates slantwise, as shown in Fig.1.
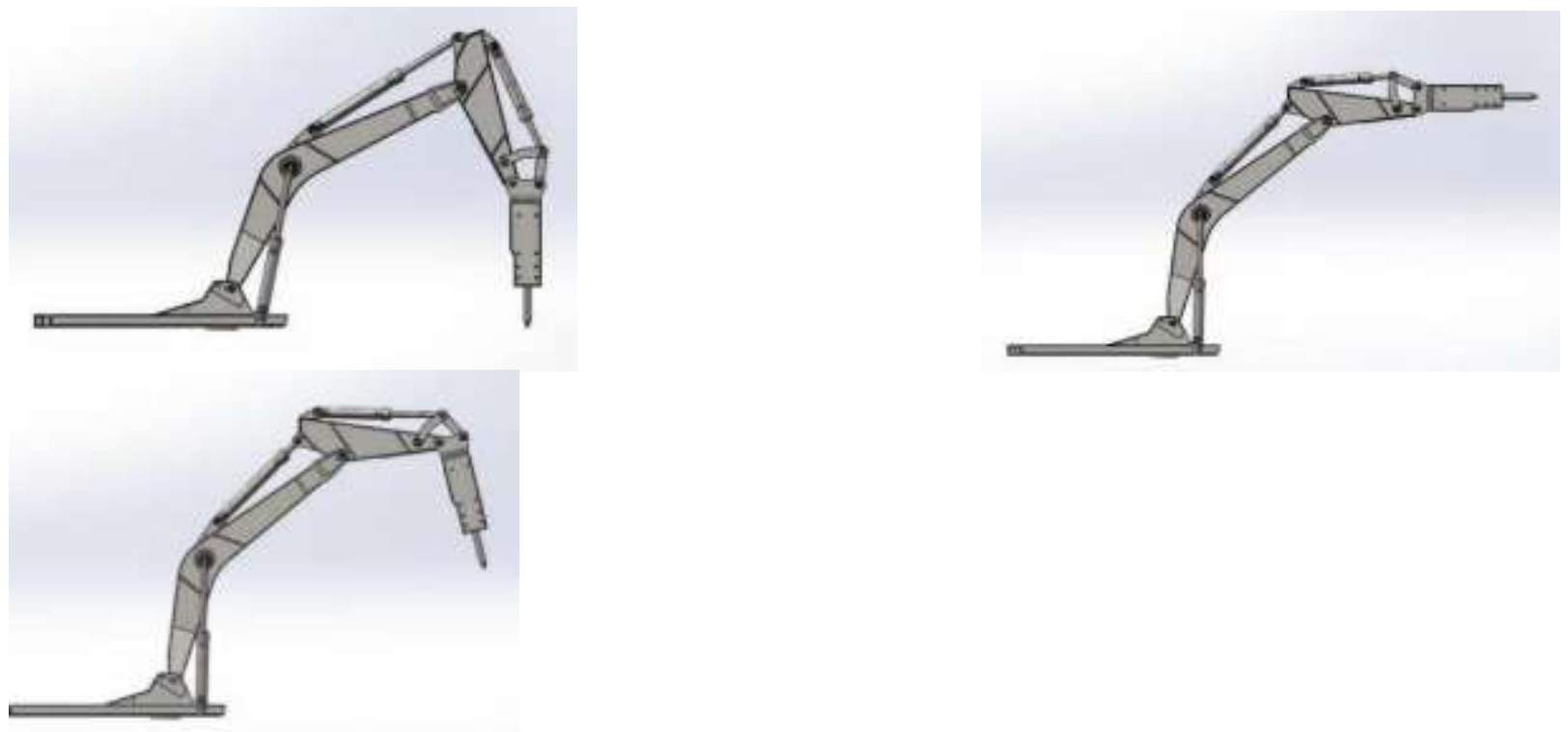

Fig 1: Selection of working condition

2.2 Load calculation of each hinge point of the movable arm

Breaking machine selected in this thesis is made in certain company whose working device consists of the breaking hammer, the movable arm, the stick, the installation platform, the breaking hammer cylinder, the stick cylinder, the movable arm stick, and other connecting pieces.

During the calculation the oil cylinder, the movable arm and the stick can be regarded as two-force bars receiving forces on both ends, without regard to forces such as friction. Therefor the whole structure can be considered to receive merely the horizontal force and the vertical force, i.e. a determinate structure.

The operation angle of the breaking hammer $\beta=90^{\circ}$ indicates vertical operation, and $\beta=180^{\circ}$ means horizontal operation. As for the slanting operation, take random angle $\beta=75^{\circ}$.

(1)Only independent dynamic analysis of the breaking hammer is considered in which force on the end of the drill rod is along the drill rod and vertical to the end face of the drill rod. Force analysis of the breaking hammer is shown in Fig.2.

ISSN: 0010-8189

(C) CONVERTER 2020

www.converter-magazine.info 
Fig 2: Force analysis of the breaking hammer

Balance equation below is drawn from force analysis of the breaking hammer as shown in Fig.2.

$$
\left\{\begin{array}{l}
\sum F_{x}=0 \\
-F_{1} \cos \beta+P_{x}-F_{q} \cos \theta_{1}=0 \\
\sum F_{y}=0 \\
F_{1} \sin \beta-G_{1}+P_{y}+F_{q} \sin \theta_{1}=0 \\
\sum M_{p}=0 \\
-F_{1} \cos \beta L_{N P y}+F_{1} \sin \beta L_{N P x}-G_{1} L_{O_{1} P x} \\
+F_{q} \sin \theta_{1} L_{Q P x}-F_{q} \cos \theta_{1} L_{Q P y}=0
\end{array}\right.
$$

(2) Independent dynamic analysis of Point $\mathrm{M}$ is shown in Fig.3

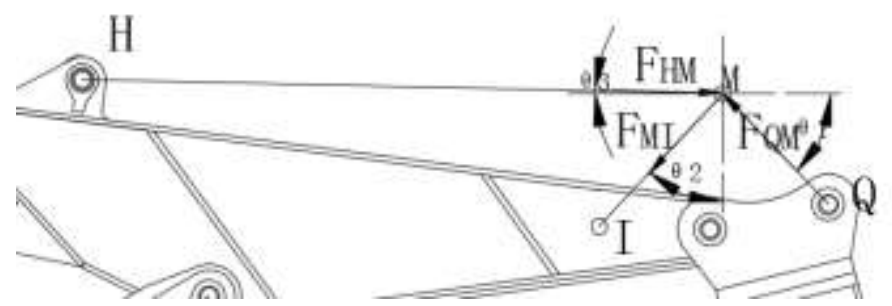

Fig 3: Force analysis on point $M$

The following balance equation is drawn from force analysis of Point M shown in Fig.3.

$$
\left\{\begin{array}{l}
\sum F_{x}=0 \\
-F_{Q M} \cos \theta_{1}-F_{M I} \sin \theta_{2}+F_{H M} \cos \theta_{3}=0 \\
\sum_{y} F_{y}=0 \\
F_{Q M} \sin \theta_{1}+F_{M I} \cos \theta_{2}-F_{H M} \sin \theta_{3}=0 \\
F_{q}=F_{Q M}
\end{array}\right.
$$

(3) With independent dynamic analysis of the stick, size and direction of force in the breaking hammer can be obtained according to Formula 1, and sizes and directions of forces in Point M, Point H, Point P can be obtained according to Formula 2. The values above are regarded as known ones in solution of the force in the stick. Stress situation of the stick is shown in Fig.4 


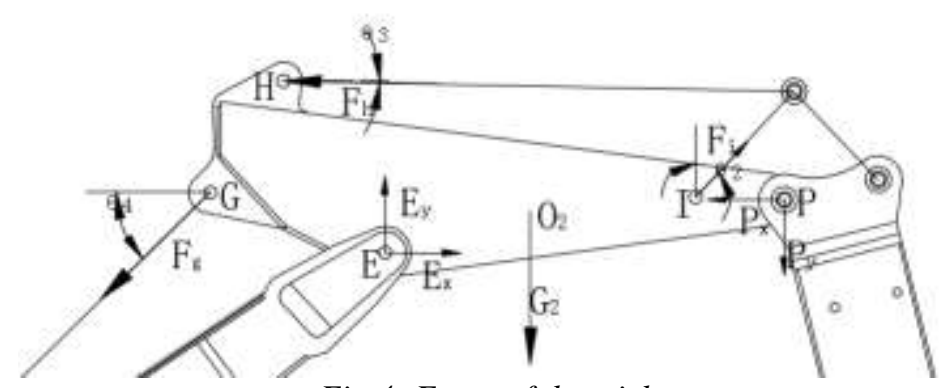

Fig 4: Force of the stick

The following balance equation is drawn from stress situation of the stick shown in Fig.4.

$$
\left\{\begin{array}{l}
\sum F_{x}=0 \\
-P_{x}+F_{i} \sin \theta_{2}+E_{x}-F_{g} \cos \theta_{4}-F_{h} \cos \theta_{3}=0 \\
\sum F_{y}=0 \\
-P_{y}+F_{i} \cos \theta_{2}-G_{2}-F_{g} \sin \theta_{4}+F_{h} \sin \theta_{3}=0 \\
\sum_{E}=0 \\
-P_{y} L_{P E x}+P_{x} L_{P E y}+F_{i} \cos \theta_{2} L_{I E x}-F_{i} \sin \theta_{2} L_{I E y}-G_{2} L_{O_{2} E x} \\
+F_{h} \cos \theta_{3} L_{H E y}-F_{h} \sin \theta_{3} L_{H E x}+F_{g} \cos \theta_{4} L_{G E y}+F_{g} \sin \theta_{4} L_{G E x}=0 \\
F_{i}=F_{M I} \\
F_{h}=F_{H M}
\end{array}\right.
$$

With independent dynamic analysis of the movable arm, the oil cylinder supporting the stick can be regarded as member bar receiving force from both ends, as shown in Fig.5.

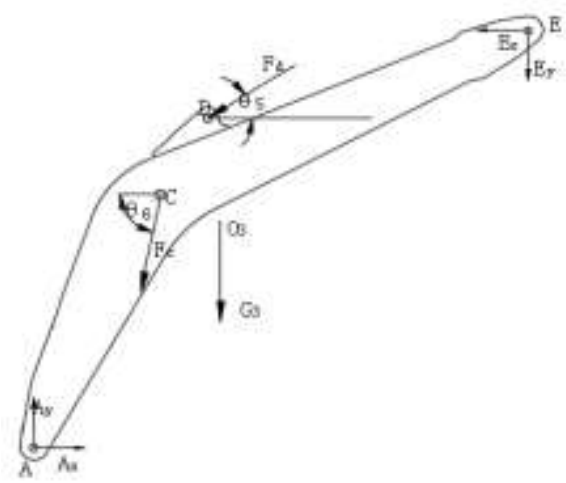

Fig 5: Force of the movable arm

The following balance equation can be drawn from the force of the movable arm shown in Fig. 5 . 


\subsection{Calculation result of load}

$$
\left\{\begin{array}{l}
\sum_{x}=0 \\
A_{x}+F_{c} \sin \theta_{5}-F_{d} \cos \theta_{4}-E_{x}=0 \\
\sum_{y} F_{y}=0 \\
A_{y}+F_{c} \cos \theta_{5}-G_{3}-F_{d} \sin \theta_{4}-E_{y}=0 \\
\sum_{A}=0 \\
-F_{c} \sin \theta_{5} L_{C A y}+F_{c} \cos \theta_{5} L_{C A x}-G_{3} L_{O_{3} A x} \\
+F_{d} \cos \theta_{4} L_{D A y}-F_{d} \sin \theta_{4} L_{D A x}+E_{x} L_{E A y}-E_{y} L_{E A x}=0 \\
F_{d}=F_{g}
\end{array}\right.
$$

The given load of the end of the breaking hammer drill rod is $200 \mathrm{kN}$, with respective values in three working conditions $\beta=90^{\circ}, \beta=180^{\circ}, \beta=75^{\circ}$. Build a model for detailed calculation based on concrete parameters of the movable machine, and evaluate the respective loads at the hinge points under the three working conditions, numerical values shown in the following Table 1.

Table 1 Loads of each hinge point of the movable arm $(\mathrm{kN})$

\begin{tabular}{|l|l|l|l|l|l|l|}
\hline & $A_{x}$ & $A_{y}$ & $F_{c}$ & $F_{d}$ & $E_{x}$ & $E_{y}$ \\
\hline Working condition one & 504 & 668 & 212 & 263 & 242 & 263 \\
Working condition two & 319 & 1849 & 1747 & 64 & 235 & 57 \\
Working condition three & 127 & 65 & 223 & 167 & 13 & 114 \\
\hline
\end{tabular}

\section{Modal Analysis}

\subsection{Modal analysis theory}

The basic solution method for dynamic analysis is modal analysis, usually providing foundation for other dynamic analysis. Modal analysis helps the structure with dynamic characteristic prediction, with natural frequency and vibration mode. It is vital in prevent resonance [9] [10].

Dynamic questions abide by the following balance equation [11],

$$
[M] \ddot{X}+[C] \dot{X}+[K] X=F(t)
$$

herein $[\mathrm{M}]$ represents mass matrix, $[\mathrm{C}]$ damping matrix, $[\mathrm{K}]$ stiffness matrix, $X$ displacement vector, $F(t)$ force vector, $\dot{X}$ velocity vector, $\ddot{X}$ acceleration vector, t time.

When $f(t)=0$, irrespective of effect of damp C,

$$
[M] \ddot{X}+[K] X=0
$$

the vibration of the structure is simple harmonic vibration, its displacement function being

$$
X=X \sin (\omega t)
$$

In conclusion

$$
\left([K]-\omega^{2}[M]\right) X=0
$$

In this equation, the characteristic value is $\omega_{i}^{2}$, natural frequency $f=\frac{\omega_{i}}{2 \pi}$, characteristic vector $X_{i}$ 
corresponding to characteristic value $\omega_{i}$ is the vibration mode corresponding to natural frequency $f=\frac{\omega_{i}}{2 \pi}$.

3. 2 Modal analysis of the movable arm

3.2.1 Finite element pretreatment

Select ANSYS software for modal analysis, and obtain the first 6 natural frequencies and vibration mode shapes of the movable arm based on the analysis.

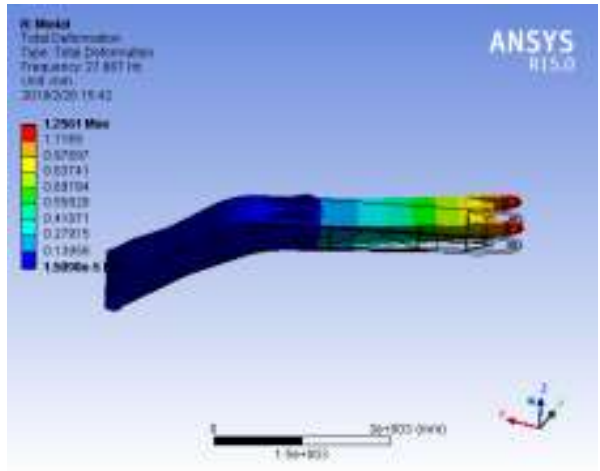

(a)First order vibration mode

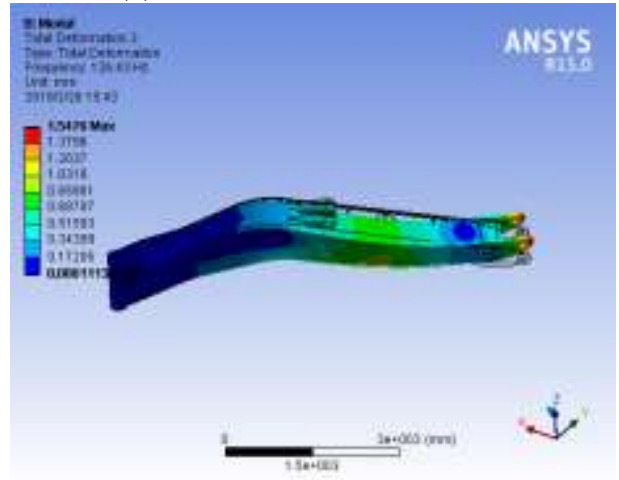

(c)Third order vibration mode

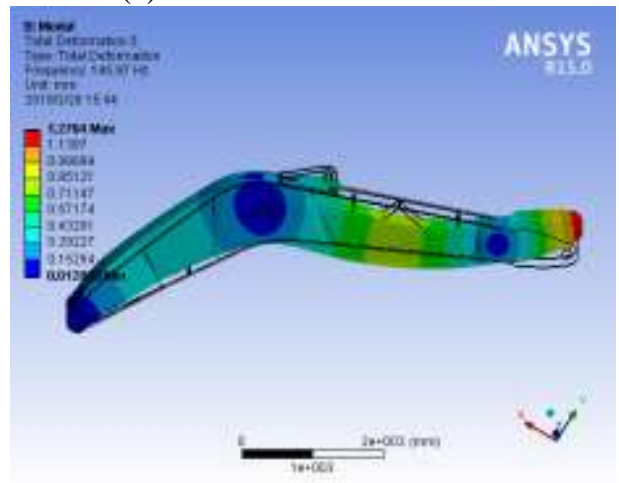

(e)Fifth order vibration mode

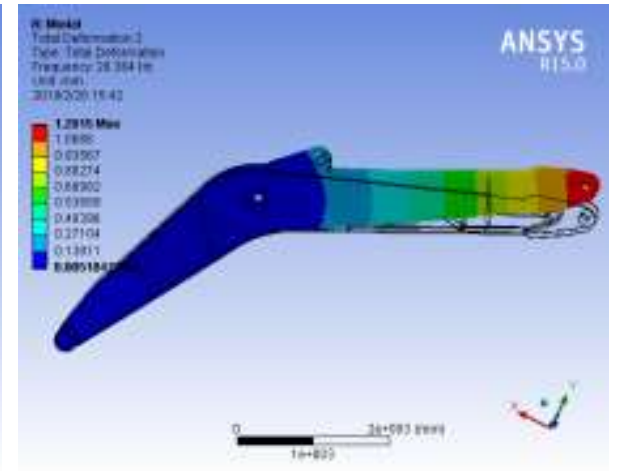

(b)Second order vibration mode

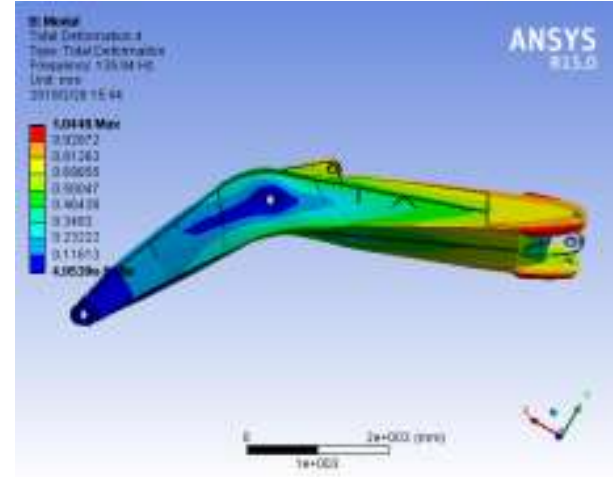

(d)Fourth order vibration mode

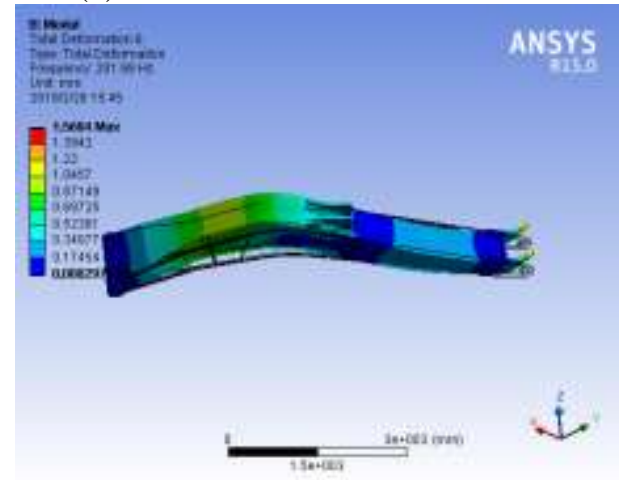

(f)Sixth order vibration mode

Fig 6: Modal vibration model of the movable arm

In the natural frequency analysis of the structure, as higher order mode has small effect on dynamic characteristics of the movable arm structure, only natural frequencies of the first six orders and their corresponding vibration modes are selected for analysis[12] [13].

Table 2 First Six orders natural frequencies of the movable arm

ISSN: 0010-8189

C) CONVERTER 2020

www.converter-magazine.info 


\begin{tabular}{|l|l|}
\hline Order & Frequency $(\mathrm{Hz})$ \\
\hline 1 & 27.667 \\
2 & 28.364 \\
3 & 126.43 \\
4 & 135.94 \\
5 & 145.97 \\
6 & 201.98 \\
\hline
\end{tabular}

Fig.6 and Table 2 suggest that natural frequency of the first order is $27.667 \mathrm{~Hz}$. The vibration mode is mainly characterized by the main vibration direction on the XY plane and offset of the connecting plate hinged between the movable arm and the stick in the positive and negative directions on Y axis. Take the hinge point between the movable arm and the movable arm cylinder as the dividing point, there is obvious deformation on the right side of this point, while there is no obvious deformation on the left side.

The natural frequency of the second order is $28.364 \mathrm{~Hz}$. The vibration mode is mainly characterized by the main vibration direction on the $\mathrm{XZ}$ plane and offset of the connecting plate hinged between the movable arm and the stick in the positive and negative directions on $\mathrm{Z}$ axis. Similarly, take the hinge point between the movable arm and the movable arm cylinder as the dividing point, there is obvious deformation on the right side of this point, while there is no obvious deformation on the left side.

The natural frequency of the third order is $126.43 \mathrm{~Hz}$. The vibration mode is mainly characterized by the main vibration direction on XZ plane and XY plane and the connecting plate of the movable arm bending along $\mathrm{Z}$ axis with noticeable deformation. There is obvious bending deformation of the edge of the connecting plate where the movable arm is hinged with the stick on the XY plane.

The natural frequency of the fourth order is $135.94 \mathrm{~Hz}$. The vibration mode is mainly characterized by the main vibration direction on XY plane and noticeable torsional deformation of the movable arm, with noticeable deformation on the edge of connecting plate where the movable arm is hinged with the stick.

The natural frequency of the fifth order is $145.94 \mathrm{~Hz}$. The vibration mode is mainly characterized by the hinge point between the movable arm and the movable arm cylinder taken as the dividing point. There is noticeable bending deformation in the right part along the $\mathrm{Y}$ axis, and there is obvious deformation in the left part along $\mathrm{Z}$ axis.

The natural frequency of the sixth order is $201.98 \mathrm{~Hz}$. The vibration mode is mainly characterized by the hinge point connecting the movable arm and the movable arm cylinder taken as dividing point. The left part is obviously depressed and deformed along the $\mathrm{Z}$ axis, while connecting plate and the flange plate on the right side are slightly bent and deformed. There is obvious bending deformation along the $\mathrm{Z}$ axis on the edge of the connecting plate hinged between the movable arm and the stick.

Calculation of the six natural frequencies of the movable arm and analysis of its vibration mode suggest that with the increase of natural frequency, the movable arm changes from displacement deformation in a single direction to torsional bending deformation gradually, and the deformation becomes more and more complicated.

The working frequency of the engine is about $30-60 \mathrm{~Hz}$, and the striking frequency of the breaking hammer is about $8-14 \mathrm{~Hz}$. As the natural frequency of the movable arm is different from that of the breaking machine's engine and of the breaking hammer, resonance will not occur.

\section{Harmonic Response Analysis}

\subsection{Harmonic response analysis theory}

When the structure is under sinusoidal load with given frequency and amplitude, harmonic response analysis is required to determine the steady-state response of the structure under these external conditions [14]. The steady-state response of the movable arm under external load can be obtained through harmonic response analysis, and the external load corresponding to the peak frequency is analyzed through the curve of response value (usually displacement) and frequency[15].

ISSN: 0010-8189

(C) CONVERTER 2020

www.converter-magazine.info 
Under the action of dynamic load, mechanical structure produces vibration, which is likely to cause mechanical structure failure. Transient excitation load in dynamic load will produce huge vibration response to the structure in a short time, which will have a great impact on the service life of the mechanical structure and the health of workers, so it is necessary to study harmonic response analysis[16]

Dynamic problems all follow the following equilibrium equations[17] ,

$$
\begin{gathered}
{[M] \ddot{X}+[C] \dot{X}+[K] X=f(t)} \\
f(t)=f_{0} \cos (\omega t)
\end{gathered}
$$

where $[\mathrm{M}]$ is a mass matrix; (c) is a damping matrix; $[\mathrm{K}]$ is a stiffness matrix; $\mathrm{X}$ is the displacement vector; $f(t)_{\text {is }}$ the force vector; $\dot{X}$ is the velocity vector; $\ddot{X}$ is the acceleration vector; $\mathrm{T}$ is time.

In the previous modal analysis, we have obtained that the maximum natural vibration frequency of the movable arm is $201.98 \mathrm{~Hz}$. In harmonic response analysis, the maximum top limit frequency is 1.5 times smaller than the maximum value of modal analysis (i.e. the sixth order natural frequency) [18], so the maximum frequency input in harmonic response analysis needs to be less than $134.65 \mathrm{~Hz}$.

\subsection{Harmonic response analysis of the movable arm}

Two response points are respectively selected from the movable arm structure for analysis of their dynamic characteristics under three working conditions, as shown in Fig.7. The reason for selecting response point 1 is that the root area of the ear plate is prone to fatigue damage due to the frequent operation of the oil cylinder hinging the stick and movable arm; the reason for selecting the response point 2 is that there is a remarkable deformation in the hinging area between the movable arm and the stick based on the results of both static analysis and modal analysis.

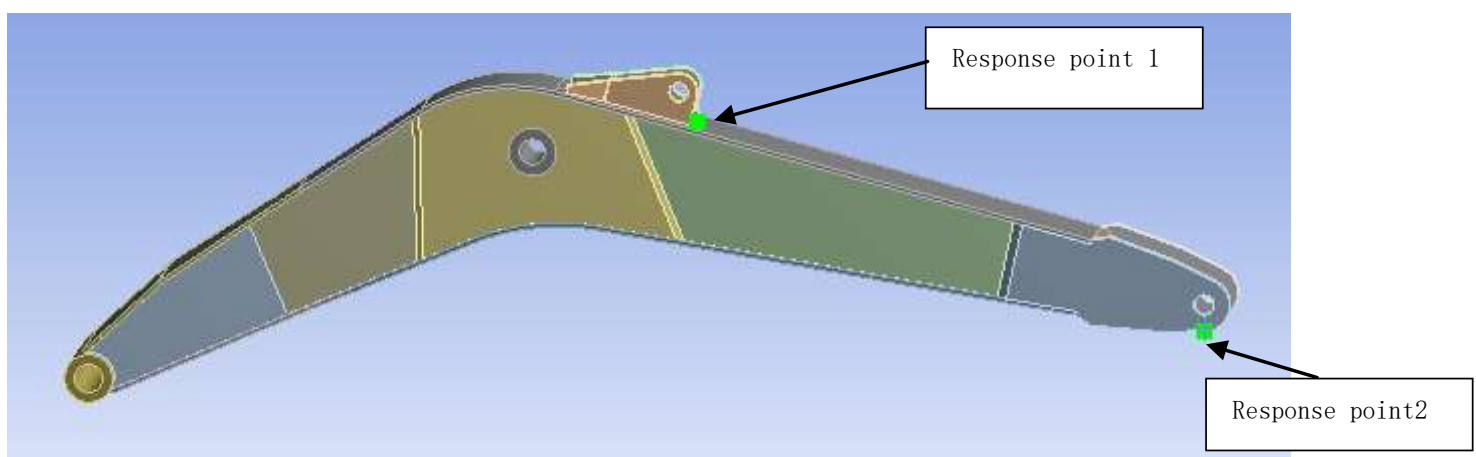

Fig 7: Response point location

The relation curve between response amplitude and excitation frequency of the two response points can be obtained via finite element analysis software and harmonic response analysis.

(1)Under working condition 1, the response curves of response points 1 and 2 are as follows.
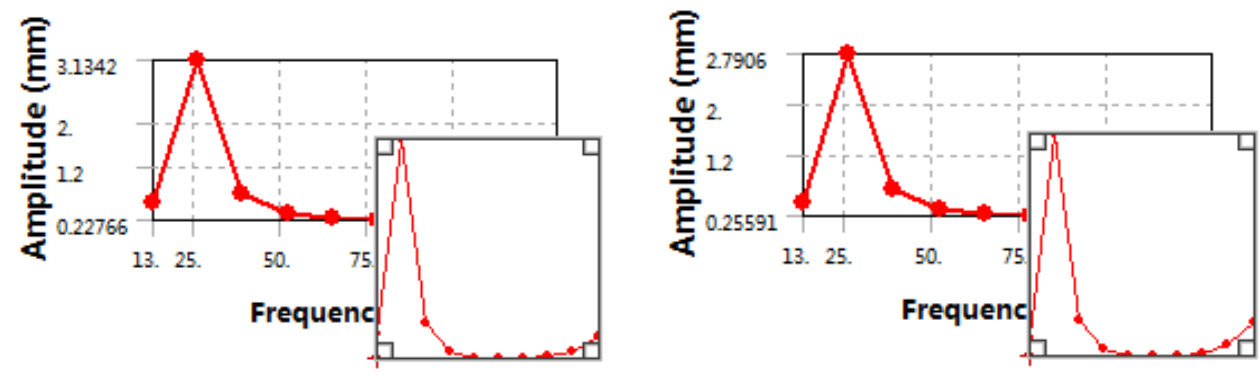

ISSN: 0010-8189

C CONVERTER 2020

www.converter-magazine.info 


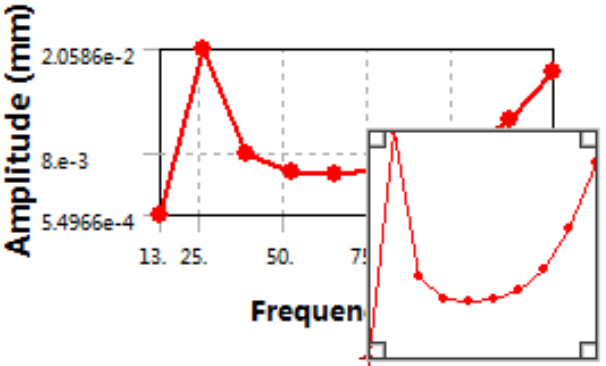

Fig 8: Relation curve of response amplitude and excitation frequency of response point 1 in $X, Y$ and $Z$ directions under working condition 1

As can be seen from the above figure 8 , when the load frequency is $26 \mathrm{~Hz}$, the maximum response displacement occurs in the $\mathrm{X}$ direction, with a value of $3.1342 \mathrm{~mm}$. When the load frequency is $13 \mathrm{~Hz}$, the response displacement value occurring in $\mathrm{X}$ direction is $0.54887 \mathrm{~mm}$. When the load frequency is $39 \mathrm{~Hz}$, the response displacement value is $0.69625 \mathrm{~mm}$. The response displacement increases from $0.54887 \mathrm{~mm}$ to the maximum value in the interval of $13 \mathrm{~Hz}$ to $26 \mathrm{~Hz}$. In the interval of $26 \mathrm{~Hz} \sim 39 \mathrm{~Hz}$, the response displacement decreases from the maximum value to 0.69625 $\mathrm{mm}$. The response displacements in other frequency domains are relatively small.

When the load frequency is $26 \mathrm{~Hz}$, the maximum response displacement occurs in the $\mathrm{Y}$ direction, with a value of $2.7906 \mathrm{~mm}$. When the load frequency is $39 \mathrm{~Hz}$, the response displacement value is $0.66717 \mathrm{~mm}$. The response displacement increases from $0.45897 \mathrm{~mm}$ to the maximum in the interval of $13 \mathrm{~Hz}$ to $26 \mathrm{~Hz}$. In the interval of $26 \mathrm{~Hz} \sim 39 \mathrm{~Hz}$, the response displacement decreases from the maximum value to $0.66717 \mathrm{~mm}$. Response displacements in other frequency domains are relatively small.

The response displacement tends to increase when the load frequency in $\mathrm{Z}$ direction is between $13 \mathrm{~Hz}$ and $26 \mathrm{~Hz}$. When it reaches $26 \mathrm{~Hz}$, the maximum response displacement value $2.0586 \mathrm{e}-002 \mathrm{~mm}$ occurs, and then starting to decrease. When the load frequency is $13 \mathrm{~Hz}$, the response displacement value is $1.7972 \mathrm{e}-002 \mathrm{~mm}$, the second largest value of response displacement in the $\mathrm{Z}$ direction, yet relatively small on the whole.
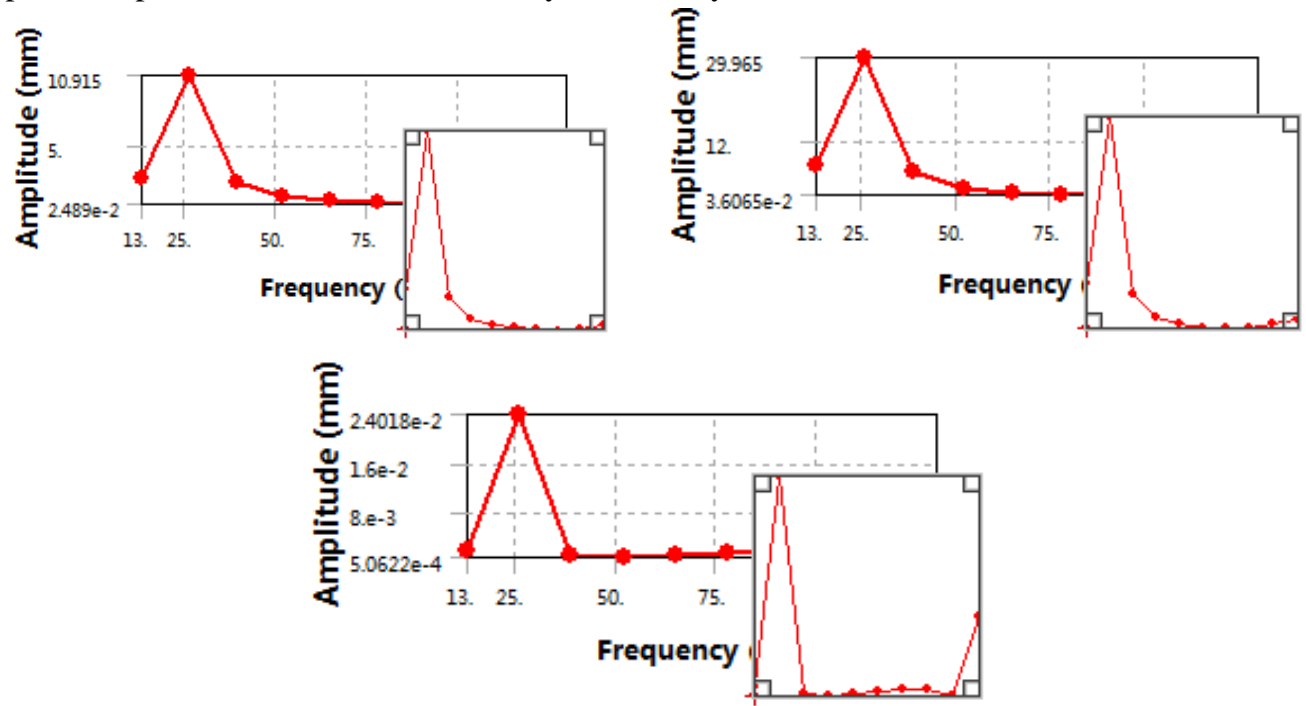

Fig 9: Relation curve of response amplitude and excitation frequency of response point 2 in $X, Y$ and $Z$ directions under working condition 1

As can be seen from the above Fig. 9, the maximum response displacement of the response point $210.915 \mathrm{~mm}$ occurs in the $\mathrm{X}$ direction, when the excitation load frequency is $26 \mathrm{~Hz}$. When the excitation load is between $13 \mathrm{~Hz}$ and $39 \mathrm{~Hz}$, the response displacement increases from $2.2714 \mathrm{~mm}$ to the maximum in the interval of $13 \mathrm{~Hz} \sim 26 \mathrm{~Hz}$; in the range of

ISSN: 0010-8189

(C) CONVERTER 2020

www.converter-magazine.info 
$26 \mathrm{~Hz} \sim 39 \mathrm{~Hz}$, the response displacement decreases from the maximum value to $1.8558 \mathrm{~mm}$. The response displacement at other frequencies is very small and tends to be stable.

When the load frequency is $26 \mathrm{~Hz}$, the maximum response displacement, $29.965 \mathrm{~mm}$, appears in the Y direction. Between $13 \mathrm{~Hz}$ and $39 \mathrm{~Hz}$, the response displacements are respectively $6.3267 \mathrm{~mm}$ and $4.9551 \mathrm{~mm}$. Between $13 \mathrm{~Hz} \sim$ $26 \mathrm{~Hz}$, the response displacement increases from $6.3267 \mathrm{~mm}$ to the maximum value. Between $26 \mathrm{~Hz} \sim 39 \mathrm{~Hz}$, the response displacement decreases from the maximum value to $4.9551 \mathrm{~mm}$. The response displacement is very small and does not change much at other frequencies. The maximum response displacement in the $\mathrm{Z}$ direction $2.4018 \mathrm{e}-002 \mathrm{~mm}$ occurs when the excitation load is $26 \mathrm{~Hz}$. A large response displacement value occurs under $13 \mathrm{~Hz}$, but the response displacement in the $\mathrm{Z}$ direction is small on the whole.

(2)The response curves of response point 1 and response point 2 under working condition 2 are as follows.
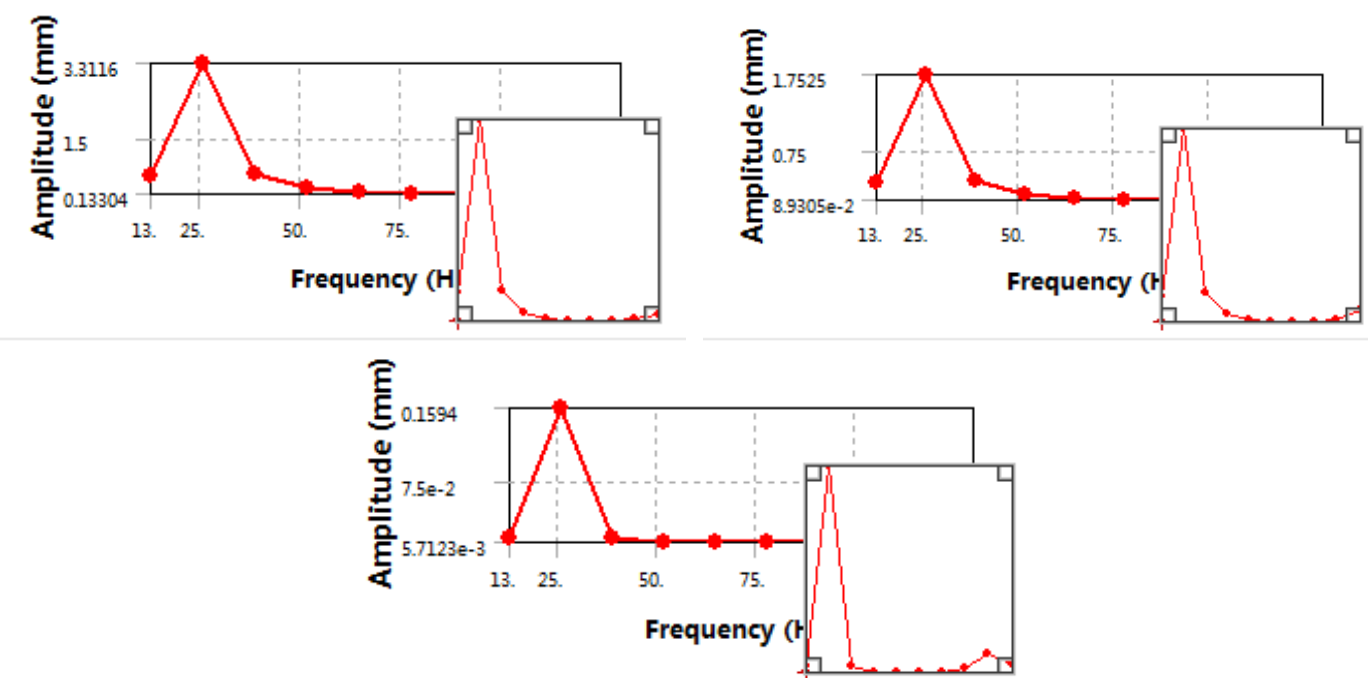

Fig 10: The relation curve between response amplitude values of response point 1 in $X, Y$ and $Z$ directions and the excitation frequencies under working condition two

It can be seen from the above Fig. 10 that when the excitation load frequency is $26 \mathrm{~Hz}$, the maximum response displacement of the response point 1 in the $\mathrm{X}$ direction is $3.3116 \mathrm{~mm}$. The maximum response displacement in the $\mathrm{Y}$ direction is $1.7525 \mathrm{~mm}$. The maximum response displacement in the $\mathrm{Z}$ direction is $0.1594 \mathrm{~mm}$. On the whole, the response displacement values are relatively small. When the excitation load frequency is $26 \mathrm{~Hz}$, the response displacements in the three directions are rather large, and when the excitation load frequency is $39 \mathrm{~Hz}$, the response displacement is very small and the curve is relatively stable.
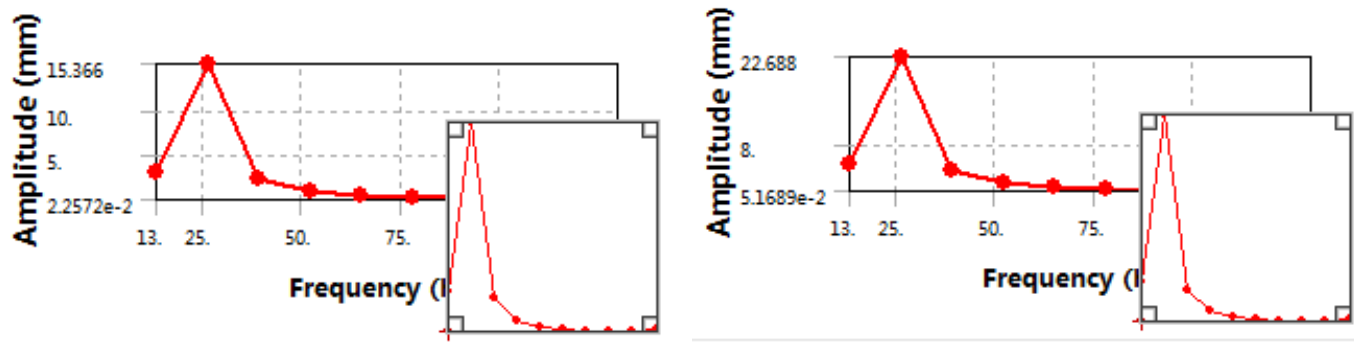

ISSN: 0010-8189

C CONVERTER 2020

www.converter-magazine.info 


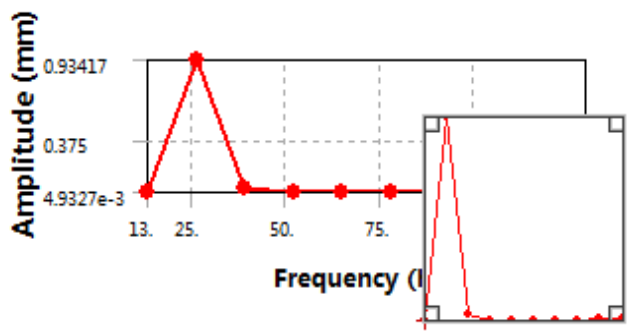

Fig 11: The relation curve between response amplitude values of response point 2 in $\mathrm{X}, \mathrm{Y}$ and $\mathrm{Z}$ directions and the excitation frequencies under working condition two

As shown in Fig. 11, when the excitation load frequency is $26 \mathrm{~Hz}$, the maximum response displacement of response point 2 in the $\mathrm{X}$ direction is $15.366 \mathrm{~mm}$. The maximum response displacement $22.68 \mathrm{~mm}$ occurs in $\mathrm{Y}$ direction, and the maximum response displacement in the $\mathrm{Z}$ direction is $0.93417 \mathrm{~mm}$. The response displacements in the three directions are rather large when the excitation load frequency is around $26 \mathrm{~Hz}$. The response displacements are small under excitation load frequency $39 \mathrm{~Hz}$, and the curve is relatively stable.

(3)Under working condition 3, the response curves of response point 1 and response point 2 are as follows.
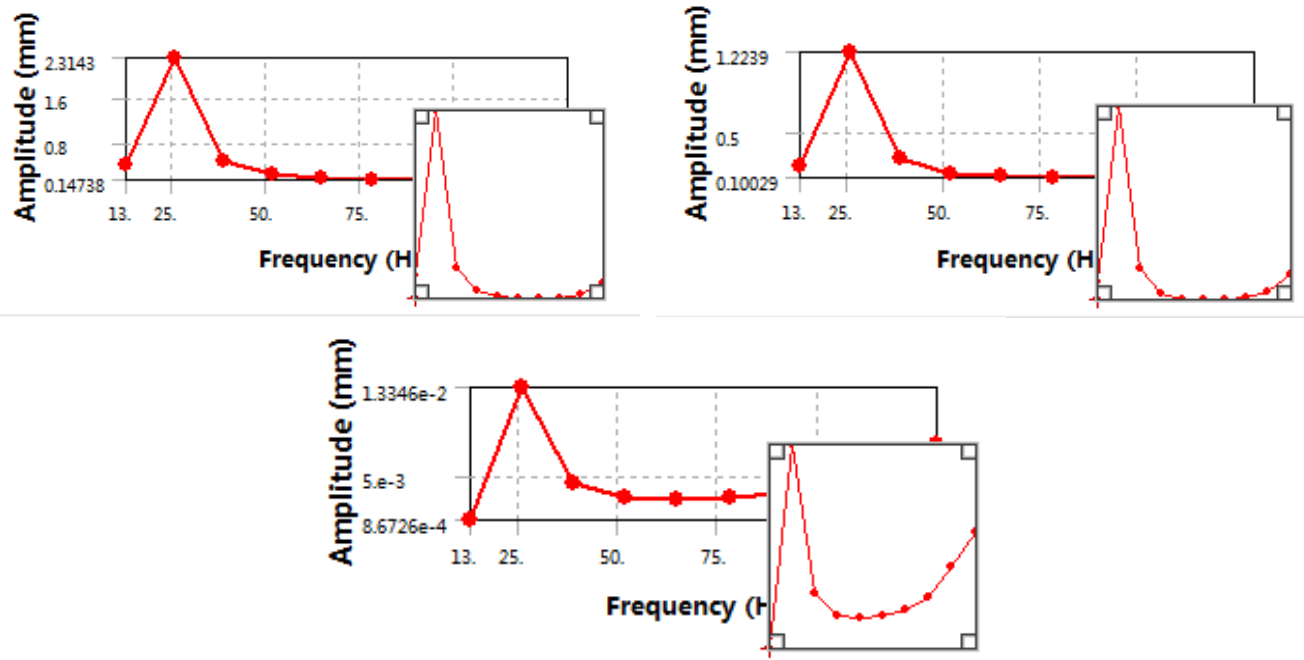

Fig 12: Relation curves between response amplitude values of response point 1 in $X, Y$ and $Z$ directions and excitation frequency under working condition 3

It can be seen from the above Fig. 12 that when the excitation load frequency is $26 \mathrm{~Hz}$, the maximum value of response displacement $2.3143 \mathrm{~mm}$ appears in the $\mathrm{X}$ direction. The maximum response displacement in the $\mathrm{Y}$ direction is $1.2239 \mathrm{~mm}$. When the excitation load frequency reaches above $39 \mathrm{~Hz}$, the response displacements in $\mathrm{X}$ and $\mathrm{Y}$ directions are very small and the curve is relatively stable. When the excitation load frequency is $26 \mathrm{~Hz}$, the maximum response displacement in the $\mathrm{Z}$ direction is $1.3346 \mathrm{e}-002 \mathrm{~mm}$, and the response displacement in the $\mathrm{Z}$ direction is relatively small on the whole.
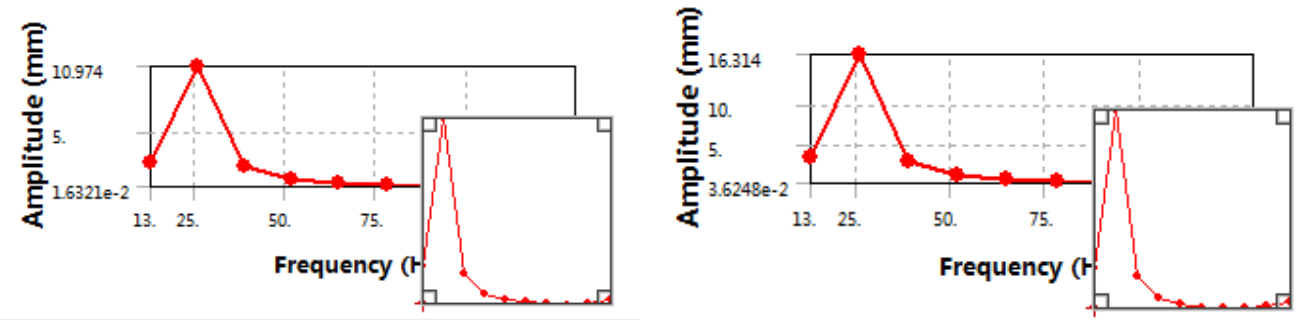

ISSN: 0010-8189

C CONVERTER 2020

www.converter-magazine.info 


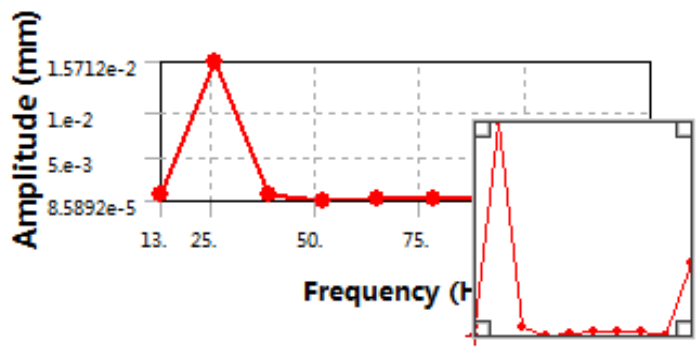

Fig 13: Relation curve between $X, Y$, and $Z$ directions response amplitude values and excitation frequencies of response point 2 under working condition 3

As shown in Fig. 13, when the excitation load frequency is $26 \mathrm{~Hz}$, the maximum response displacement of the response point $210.974 \mathrm{~mm}$ appears in the $\mathrm{X}$ direction, and the maximum response displacement in the $\mathrm{Y}$ direction is $16.314 \mathrm{~mm}$. When the excitation load frequency reaches above $39 \mathrm{~Hz}$, the response displacements in the $\mathrm{X}, \mathrm{Y}$ directions are very small and the curve is relatively stable. When the excitation load frequency is $26 \mathrm{~Hz}$, the maximum value of response displacement appears in the $\mathrm{Z}$ direction, which is $1.5712 \mathrm{e}-002 \mathrm{~mm}$, and the response displacement is very small. On the whole, the response displacement in the $\mathrm{Z}$ direction is small.

\section{Conclusion}

Three typical working conditions of the breaking machine are selected in this thesis, and the loads of each hinged point of the movable arm under each working condition are solved, and the modal analysis and harmonic response analysis are mainly carried out for the movable arm. By analyzing the relationship between the vibration modes and the calculated natural frequencies, deformation of the movable arm under the first six natural frequencies can be obtained. It is found that the maximum response displacement of the movable arm is likely to occur under low frequencies, which means that resonance effect is likely to occur.

Through harmonic response analysis, the dynamic response of the movable arm under external excitation load is obtained. When the external excitation load frequency is $26 \mathrm{~Hz}$, the maximum response displacement of the movable arm appears, which is approximate to the first-order natural frequency of the movable arm. Therefore, resonance can be effectively avoided when the external excitation load avoids the first two natural frequencies of the movable arm. It can be seen that the external excitation load has great influence on the movable arm at lower frequencies, so it is necessary to increase the damping of the working device of the breaking machine, so that the first and second natural frequencies of the external excitation frequency can be avoided, thus reducing the possibility of resonance of the movable arm.

\section{References}

[1] G. Ramesh; V. N. Krishnareddy, T. Ratnareddy. "Design and Optimization of Excavator", International Journal of Recent Trends in Enginee-ring \& Research, vol. 32, no. 4, Apr, pp. 535-549, 2017.

[2] W R Luo, Q Zhang. "Engineering application of excavator driving steel pipe pile on water with breaking hammer", City \& House, vol. 27, no. 11, Nov, pp. 219-220, 2020.

[3] Chinta Ranjeet Kumar; BH Sridhar; J. Pradeep Kumar. "Modeling and Analysis of Excavator Bucket with Replacing Material", International Journal Magazine of Engineering, Technology, Management and Research. vol. 44, no. 11, Nov, pp. 115-121, 2017.

[4] M S Zhang, Z C Su, Wang Hong. "Research on Dynamic Characteristics of Hydraulic Breaker", China Southern Agricultural Machinery, vol. 52, no. 02, Feb, pp. 106-109, 2021.

[5] Q Q Du, J Cai. "Introduction of Russian heavy machinery group company ", Heavy Casting and Forging, vol. 33, no. 4, Jun, pp. 42-47, 2017.

[6] Janmit, RajGaurav Saxena, Rishi Kumar, Kuldeep Kaushik. "Study on the Analysis of Excavator Boom:

ISSN: 0010-8189

(C) CONVERTER 2020 
A Review", SSRG International Journal of Mechanical Engineering (SSRG-IJME), vol. 32, no.7, Jul., pp. 31-39, 2015.

[7] E L Zhang, L Hou. "Hypermesh-based modal analysis on hydraulic hammer working devices", Chinese Journal of Construction Machinery, vol. 13, no. 5, May, pp. 423-428, 2015.

[8] Asit Kumar Choudhary, Gian Bhushan. "Finite Element Analysis of an Excavator Arm using CAE Tool ", International Journal of Scientific \& Engineering Research, vol. 28, no. 4, Apr, pp. 1058-1063, 2017.

[9] H Wang. Identification Method of Modal Parameters of Mechanical System and Its Application, PhD Thesis, Northeastern University, 2002.

[10] J N Huang, X Wang, S L Liu, "Finite Element Analysis and Optimal Design for Hydraulic Excavator Mobile Arm", Tractor \& Farm Transporter, vol. 46, no. 8, Aug, pp. 29-32, 2019.

[11] Sun Keyi. Dynamic Analysis and Simulation of Working Device of Hydraulic Excavator, PhD Thesis, Lanzhou University of Technology, 2014.

[12] Niteen S. Patil, Prof. Vinay. M. malbhage. "FEA Analysis and Optimization of Boom of Excavator", International Conference on Ideas, IMPact and Innovation in Mechanical Engineering (ICIIIME 2017), vol. 25, no. 6, Jun, pp. 635-632, 2017.

[13] H Y Kang. Dynamic Analysis of the Movable Arm Structure of Hydraulic Excavator, PhD Thesis, Changsha University of Technology, 2007.

[14] C Z Zhong, G Yan. "The Harmonic Response Analysis of Engine Block Based on Modal Analysis", Applied Mechanics and Materials, vol. 13, no. 8, Aug pp. 246-251, 2012.

[15] G Y Yang, H Y Guo, etc. "ANSYS Dynamic Analysis of Main Components of Vibration Charge System", Mechanical Design and Manufacturing, vol. 33, no. 11, Nov, pp. 9-10, 2008.

[16] H J Jiang. Study on Dynamic Characteristics of Portal Crane Arm System under Lifting Dynamic Load Excitation, PhD Thesis, Wuhan University of Technology, 2006.

[17] C Y Zou, F Ren, Z J Yang. Harmonic Response Analysis of Main Shaft Device of Single Rope Winding Hoist Based on ANSYS WORKBENCH, Coal Engine, vol. 49, no. 3, Mar, pp. 100-106, 2017.

[18] G J Yi. "Finite Element Analysis and Optimization Design of Excavator Boom. Modern Manufacturing Technology and Equipment", vol. 53, no. 7, Jul, pp. 91-92, 2018. 